\title{
Study on the isothermal forging process of MB26 magnesium alloy adaptor
}

\author{
Wenchen Xu, Chuan Yang, Debin Shaninst ${ }^{\mathrm{a}}$, Fuchang Xu, Guan Wang, and Bin Guo \\ School of Materials Science and Engineering, Harbin Institute of Technology, Harbin 150001, \\ PR China
}

\begin{abstract}
The isothermal forging process is an effective method to manufacture complexshaped components of hard-to-work materials, such as magnesium alloys. This study investigates the isothermal forging process of an MB26 magnesium alloy adaptor with three branches. The results show that two-step forging process is appropriate to form the adaptor forging, which not only improves the filling quality but also reduces the forging load compared with one-step forging process. Moreover, the flow line is distributed along the contour of the complex-shaped adaptor forging.
\end{abstract}

\section{Introduction}

Magnesium alloys are light-weight and high-strength structural materials, which have great potential for the application of aviation, aerospace and other allied industries [1]. However, the formability of magnesium alloys is relatively low compared with other alloys due to the limited number of slip systems associated with hexagonal close packaged (HCP) crystal structure. So most of magnesium alloy components are used in the as-cast condition, which hardly satisfy the functional requirements [2]. Compared to the castings, magnesium alloys subject to plastic deformation exhibit improved mechanical properties, such as strength and ductility, loading bearing capacity, shock resistance ability, etc. Hence increasing attention is paid to hot working of magnesium alloys in recent years [3]. Isothermal precision forging is a kind of typical precision forming process widely used for manufacturing structural components of light hard-to-deform metals, such as magnesium, aluminium and titanium alloys [4, 5]. In [6] $\mathrm{Lu}$ Yan et al. successfully produced magnesium alloy upper housing of helicopter through isothermal precision forging process. However, the isothermal forging process of complex-shaped component is not easy to determine since magnesium alloys have narrow forging temperature range and poor deformability.

In the present study, the forging process of a MB26 magnesium adaptor with three branches was investigated using FE simulation and process experiment. Different forging schemes were compared and the defect mechanisms were analyzed, on the basis of which, the isothermal forging process is

\footnotetext{
${ }^{a}$ Corresponding author: shandb@hit.edu.cn
}

This is an Open Access article distributed under the terms of the Creative Commons Attribution License 4.0, which permits unrestricted use, distribution, and reproduction in any medium, provided the original work is properly cited. 

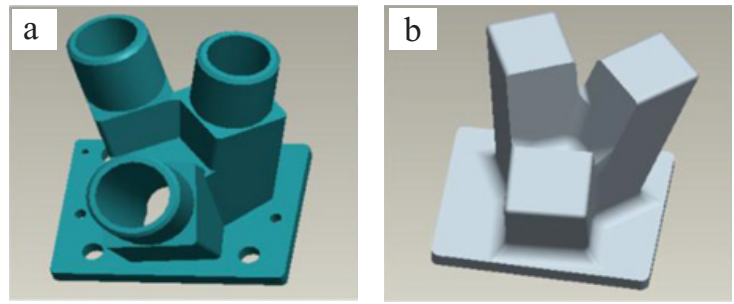

Figure 1. 3D solid modeling drawing of the MB26 magnesium adaptor: (a) component, (b) forging billet.
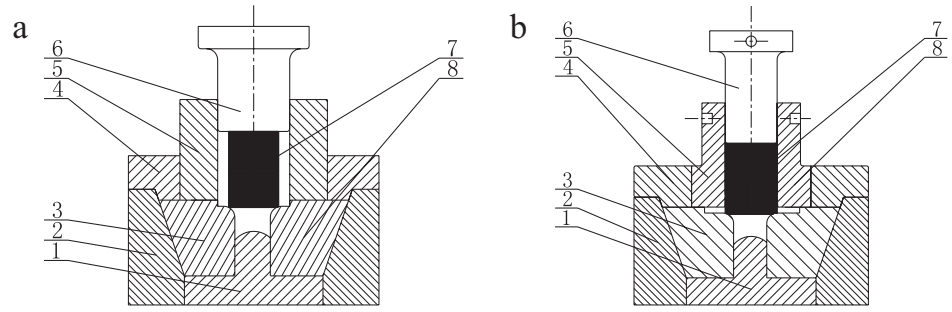

1. Insert block 2. Holder 3. Insert block 4. Pressure plate 5. Guide sleeve 6. Punch 7. Billet 8. Insert block

Figure 2. One-step forging scheme: (a) Scheme A, (b) Scheme B.

optimized. Finally, the adaptor forging of MB26 alloy was well formed with uniform distribution of flow line.

\section{Experimental material and forging schemes}

The material used in the present investigation is MB26 magnesium alloy, which belongs to $\mathrm{Mg}-\mathrm{Zn}-\mathrm{Zr}$ alloy. The MB26 magnesium alloy shows excellent mechanical properties and good hot workability [7]. Figure 1 shows the 3D solid model of the MB26 magnesium adaptor. As shown in Figs. 1(a), the MB26 magnesium adaptor contains a thin web and three branches. Due to the complex geometry of the adaptor, it is difficult to precisely form the component, so the contour of the adaptor forging is simplified considering the feasibility of the forging process. The 3D solid model of the adaptor forging is shown in Fig. 1(b). All the three branches have rectangular cross sections with the same size.

In order to remove the forging from the die after isothermal forging, a split die with vertical parting faces was designed, which was divided into four parts. In addition, a holder was designed to fix four parts of die cavity together during the forging process. To obtain the optimum forging process of the adaptor, three schemes including one-step and two-step forming processes were adopted, as shown in Figs. 2 and 3.

Scheme A and B belonged to one-step process, wherein the punch was rectangular and round in Scheme A and round in Scheme B, respectively. Scheme C was a two-step forging process, wherein three branches were formed by forward extrusion in the first step and the web was formed by upsetting in the second step.

\section{FEA model and experiment conditions}

Before the isothermal forging experiment the forging process was simulated using the 3D finite element software DEFORM ${ }^{3 \mathrm{D}}$ so as to understand die filling in the forging process. The material used for FE 


\section{ICNFT 2015}

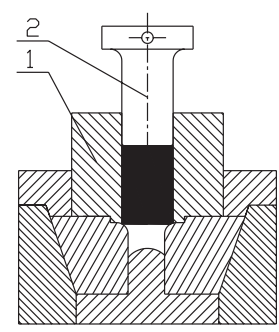

( a ) first step

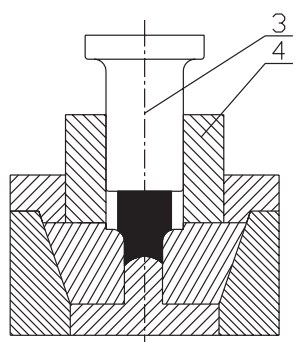

( b ) second step

1. Round guide sleeve $\quad 2$. Round punch $\quad 3$. Square punch $\quad$ 4. Square guide sleeve

Figure 3. Two-step forging scheme (Scheme C).
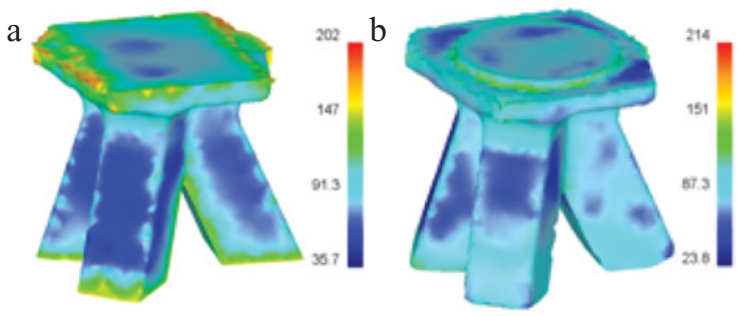

Figure 4. Distribution of equivalent stress at the distance punch travels $124 \mathrm{~mm}$ : (a) Scheme A, (b) Scheme B.

simulation was MB26 magnesium alloy. The speed of the punch was $2 \mathrm{~mm} / \mathrm{s}$. The constant friction coefficient of 0.3 was selected. The forming process was modeled at a constant temperature of $350{ }^{\circ} \mathrm{C}$.

The forging experiment was carried out on a 50,000 KN hydraulic press. The billet and the dies were lubricated with water-based graphite before heating to the working temperature. The forging temperature was kept at about $350{ }^{\circ} \mathrm{C}$ in the forging process through on-line resistance heating the combined female die. Afterwards, the adaptor forgings were subject to aging treatment at $165^{\circ} \mathrm{C}$ for $17 \mathrm{~h}$ to improve their mechanical properties. The microstructure was observed by Optical Microscopy (OM), and the mechanical properties were tested on an Instron 5569 testing machine.

\section{Results and discussion}

Based on the cylindrical billet, three forming schemes were analyzed to determine the proper forming process. Figure 4 shows the FE simulation results of one-step schemes by a square punch and round punch, i.e. Scheme A and B, respectively. Figure 5 shows the load variation during isothermal forging under various forming schemes. During the forging process, the punch pressed the billet downwards at a speed of $2 \mathrm{~mm} / \mathrm{s}$ in total time of $65 \mathrm{~s}$, moving a total distance of $130 \mathrm{~mm}$. As mentioned above, the three stages consisting of extrusion, branch filling, web filling appeared both in Scheme A and B. In the extrusion stage, the punch compressed the billet into the top cavity above three branches. In the branch filling stage, the metal flowed into three passages until touching the bottom of the female die cavity. In the web filling stage, the top of the billet was upset and the corner cavity was filled as fully as possible. But the upsetting deformation took place simultaneously on the top of the cylindrical billet in the extrusion stage of Scheme A.

In addition, the maximum load under Scheme A was much greater than that under Scheme B, as illustrated in Fig. 5. The cross section dimension of the rectangle punch was bigger than that of the top 


\section{MATEC Web of Conferences}

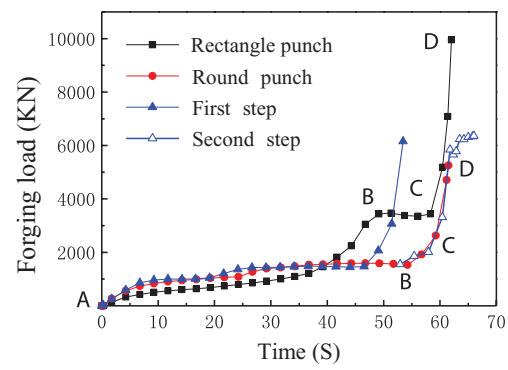

Figure 5. Variation of forging load using different forming schemes. (A-B: extrusion stage, B-C: branch filling stage, C-D: web filling stage).
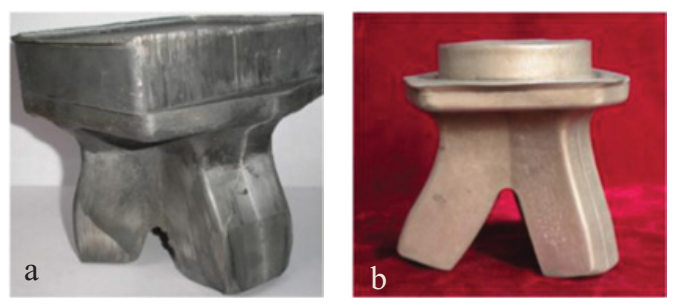

Figure 6. Underfilling defect of the adaptor forging under different schemes: (a) Scheme A, (b) Scheme B.

cavity on three branches bordering the web in Scheme A, so the forging force exerted on the web may be counteracted by the combined female die, increasing the filling resistance, while the cross section area of the round punch was nearly the same to the corresponding section in Scheme B, reducing the filling resistance. In Scheme A, Fig. 4(a), we can also find that in the web filling stage, the high stress zone was distributed on the whole web, while it localized to the center of the web in as illustrated in scheme B Fig. 4(b). Due to large flow resistance in the final filling stage, the forging load sharply increased from $4000 \mathrm{KN}$ to $10000 \mathrm{KN}$ in Scheme A, much greater than the load shown in Scheme B (Fig. 5).

However, both Scheme A and B were not able to form good adaptor forgings since some defects appeared during the forging process. The underfilling was a common defect occurring both in Scheme $\mathrm{A}$ and $\mathrm{B}$, as shown in Fig. 6. In forging practice, the metal subjected to the compression of the punch was split into three branches in the three passages of female die cavity, where the filling resistance was very large due to the reversed cone angle of three branches. Even though high punch pressure was exerted on the billet, it was counteracted by the filling resistance, increasing the difficulty in filling the die cavity of three branches. As can be seen in Fig. 4, the stresses of the bottom of three branches were very low compared to that of the web on the branches, which indicated that the plastic deformation mainly produced in the vicinity of the web and it was very hard to force the metal flow to the bottom of three branches of the female die albeit with high forging load.

Although the underfilling defect was not so evident in Scheme B as in Scheme A, the overlap as well as flow-line turbulence appeared on the web in Scheme B, as shown in Figs. 7 and 8. In Scheme B, the cross section of round punch was much smaller than the area of web, so the metal of billet flowed radially into the web cavity in the web filling process. The metal contacted the side wall of the web cavity earlier because the distance from the punch to the side wall of the web cavity was shorter than that from the punch to the corners of the web cavity. Thus the metals from two adjacent side walls close to the corner flowed towards the corners to meet together there, causing the folding defect. In addition, the flow line on the web was turbulent in that the web and three branches of the adaptor forging were formed almost simultaneously. The metal of the transitional zone between the web and the branch flowing into the web 


\section{ICNFT 2015}

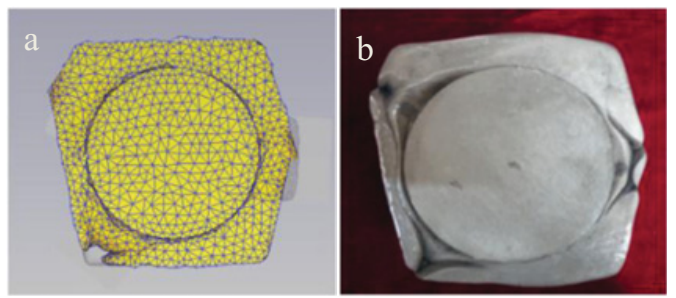

Figure 7. Folding defect of the billet in Scheme B: (a) FE simulation result, (b) experimental photo.

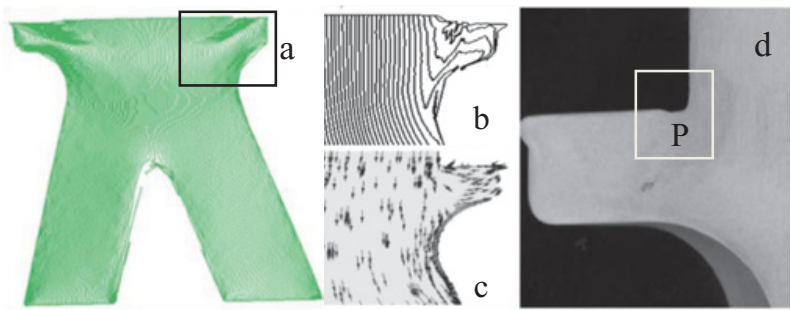

Figure 8. Flow line distribution of the adaptor forging in Scheme B: (a) flow distribution, (b) flow distribution in the web, (c) flow velocity distribution in the web, (d) experimental photo.

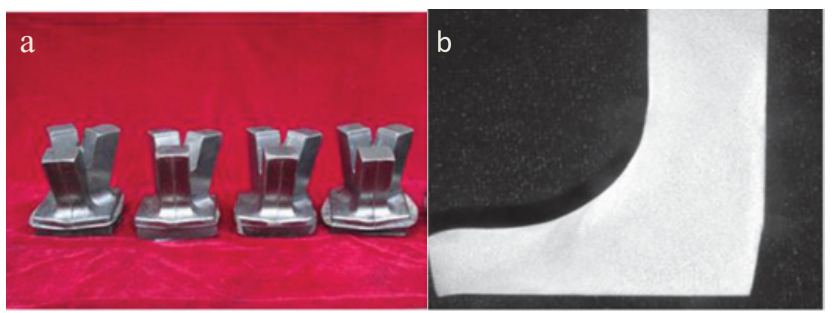

Figure 9. Photos of adaptor forgings in Scheme C: (a) final components, (b) flow line of web area.

cavity was partly dragged out from the branch cavity, so the turbulent flow line formed at Zone P, shown in Fig. 8(d).

To avoid forging defects for the adaptor forging, Scheme $\mathrm{C}$ was designed in the present study. This scheme was divided into two steps, wherein three branches was formed by forward extrusion in the first step and the web was formed by upsetting in the second step. The round punch was employed in the first step to improve the filling degree of the billet and reduced the stress exerted on the top of female die. And the square punch which had bigger cross section was employed in the second step to avoid the folding defect on the web. The two-step scheme combined the characteristics of the Scheme A and Scheme B, and the experimental results indicated better forging workpieces could be formed without forging defects, as shown in Fig. 9(a). Moreover, no turbulence of flow line was observed on the transitional zone between the web and the branch in Fig. 9(b). Additionally, the forging load in each step was relatively low, which was close to that in Scheme B, as shown in Fig. 5. Therefore, the two-step scheme was a proper process for forming the adaptor forging, which was better for saving energy and ensuring the die life. 


\section{MATEC Web of Conferences}

\section{Conclusions}

Based on FEM simulation and forging experiments, the forging process of the MB26 alloy adaptor with three branches was analyzed, the formation mechanisms of the forging defects were reveled and the optimized scheme was obtained. The results show that the combined female dies separated along the longitudinal direction of the adaptor made it feasible to remove complex adaptor with three branches from the die cavities. The forming scheme had important influence on the forming quality of the adaptor forgings. The underfilling was a common defect occurring both in Scheme A and B, and the overlap and the flow-line turbulence appeared in the web in Scheme B. In Scheme C, no forging defects were observed, and the forging load also reduced greatly. In addition, the flow line was uniformly distributed along the contour of the adaptor forging. Therefore, the cylindrical billet and the two-step forging scheme were better for forming the adaptor forging.

\section{References}

[1] H.J. Zhang, J. Meng, D.X. Tang, J. Chin. Rar. Ear. Soc., 22, 40-47 (2004)

[2] Y.Y. Li, W.W. Zhang, Y. Liu, W.P. Chen, D.H. Ni, Spec. Casting \& Nonferrous Alloys, 1, 14-17 (2004)

[3] Y.M. Hu, H. Xie, Z.F. Sun, Plast. Working Technol., 39, 5 (2004)

[4] Y.H. Qu, J.K. Sun. X.J. Meng, Tit. Ind. Prog., 23, 6-9 (2006)

[5] M.G. Yan, Hot working technol., 3, 26-28 (2003)

[6] Y. Lu, F.C. Xu, K.M. Xue, D.B. Shan, Z. Wang, Y, XU, X.Y. Kong, Y.Z. Zhao, N.H. Hao, J. Har. Ins. Tech., 32, 127-129 (2000)

[7] Z.H. Du, X.H. Zhang, X.Y. Fang, X.J. Zhang, Y.L. Chen, Y.W. Zhang, Trans. Nonferrous Met. Soc. Chin., 17, 400-404 (2007) 